\title{
Commercialization Strategy of Technology Innovation Products in Indonesia (Case Study at Agency for the Assessment and Application of Technology)
}

\author{
Anindya Pridanti Anggraeni ${ }^{1}$, Lalita Sekar Ryani ${ }^{2}$, Muhammad Nastabiq ${ }^{3}$, Fabian Wijaya ${ }^{4}$ \\ Faculty of Economics and Business, Diponegoro University, Indonesia \\ \{anindya_danti@yahoo.co.id $\left.{ }^{1}\right\}$
}

\begin{abstract}
This study examines the commercialization strategy implemented by one of the Indonesian government research institutes Agency for the Assessment and Application of Technology (BPPT) as an effort to commercialize the results of technological innovation products to increase competitiveness towards national independence. This research explains how BPPT encourages the manufacture of product and service technology through of creating innovations by developing effective strategies to commercialize technology products, how the implementation of business processes and the incubation process products. This study used a qualitative method with case study approach. The results found that BPPT launched commercialization strategy by focusing on creating technology innovation products market driven that support industrial needs. The success of product marketing is because BPPT already had users that matched the institutional targets. Other findings found that business process consists of ten stages: research, technology disclosure, assessment, intellectual property protection, technology marketing, selecting the best partner, cooperation agreement, project management, payment and royalties, and reinvest. The commercialization of technology products from research institute is more successful if supported by well preparation, planned and measurable strategic plan, so strategies in increasing the role of technology through innovation and technology services will be in line with the direction of national development.
\end{abstract}

Keywords: Technology commercialization, Product innovation, Product development, Business strategy, Qualitative approach

\section{Introduction}

The role of technology in today's globalization has important benefits to facilitate human activities. Technology is used as a tool as a result of the increasingly rapid development of science. Advances in knowledge/technology or development of needs are often considered the driving force for innovation [14]. Says that the progress of a country is based on science and technology controlled by the government so that it will be a competitive advantage. This strategy is useful for boosting economic growth in a country. 
Integrating science and technology into economic activity will transfer outstanding results for companies, especially for the country. The creation of high innovation products will make a significant difference in welfare, economy, and social. There needs to be a broad understanding of how technological knowledge is created and applied, which will drive successful economic development. Technological progress will impact increasing the industrialized world's productivity capacity both in terms of technology use in industry and the types of products to allow industrialization in a country.

Realizing an innovative product right on target is not easy because it requires a careful R\&D process. Based on track record information obtained in the 2019 Global Competitiveness Index Report, Indonesia is ranked 74th in terms of innovation capability. Then in terms of Global Competitiveness, it is ranked 50th [3]. Innovative products are often used for company business continuity because they have impressive specifications and advantages that do not exist in the market. In fact, when a company is about to realize an innovative product, they have their own challenges when carrying out the commercialization process to the end [6]. The use of the technology commercialization model is commonly applied when introducing new products to the market and is expected to simplify the marketing process. The commercialization model itself is defined as a direction toward developing strategic plans and actions to manufacture technological innovation products.

There is one non-ministerial government agency in Indonesia, namely the Agency for the Assessment and Application of Technology (BPPT), which has the function of carrying out government tasks in technology assessment and application. BPPT itself has a role in national development to develop an innovation center in Indonesia. During the commercialization of its technological innovation products, BPPT experienced several obstacles, such as experiencing constraints due to budgetary factors. It took a long time to implement and disseminate the technology used. Currently, the National Research Agency targets all types of research results, including in higher education institutions. Careful coordination will be carried out to have clear objectives and applications in terms of commercialization and downstream. This statement was conveyed in order to ensure that technology products from research results could be realized and received by the community [7]. Based on some of these constraints and demands, this study will explore the technology commercialization strategy carried out by BPPT by applying qualitative methods, and provide a complex understanding of other findings that support the main answer.

\section{Literature Review}

\subsection{Technology Commercialization}

Identifying opportunities for commercialization of technology is usually considered the most challenging task in exploiting external technology. Building a successful technology planning process in the context of open innovation is essential to gain and maintain a competitive advantage [8]. Also, research from [19] states companies that innovate have technological capabilities and opportunities to acquire their commercialization capabilities through experiential learning and allow them to commercialize their innovations under certain conditions optimally. There are other ways to commercialize where governments and universities work together to create the industry's latest knowledge-based innovations. These findings come from the research of Asad Abbas's research. 
One of the main reasons for technology to grow fast and run well in industrialized countries is because it is very concerned about commercialization. It is known that the series of commercialization activities is quite complicated because it involves various aspects consisting of the market environment, human resources, economic policy, investment, time, and others. Especially in the field of technological innovation products, the commercialization process that is carried out requires the right strategy so that the product can sell well in the market. The commercialization of technology is increasingly complicated because it involves many parties and factors. It can be concluded from the research of [6] that technology must create economic and social welfare. All of this depends on the commercialization process being carried out. According to [11] barriers that are the main factor in conducting technology commercialization are the many development projects but only a few products were launched successfully and become successful. The rest of the company's development money was spent on projects that never hit the market. In this case, it can be seen that the downstream process is the main factor causing failure. On the other hand, according to the perception of [15], cooperation will accelerate the commercialization of technology as an opportunity for competitive advantage in the industry.

\subsection{Innovation Strategy}

Innovation is defined as creating new knowledge and ideas to facilitate business results, aiming to improve internal business processes and structures and develop products and services that the market wants [5]. Innovations can be in the form of new products, new services, or new technologies. Companies generate two types of internal innovation when utilizing their R\&D activities, namely incremental and radical innovations. Most inventions are incremental by building on an existing knowledge base and providing additional or minor improvements in the current product line. Companies produce more incremental (incremental) innovations than radical innovations because production costs are cheaper, production processes are more accessible and faster, and involve less risk [5].

In contrast to incremental innovation, radical innovation usually provides significant technological breakthroughs and creates new knowledge. These innovations are revolutionary and typically use the latest technology to serve newly created markets, thus necessitating different management practices [13]. The downside of this innovation is that it often endangers businesses because it is difficult to commercialize. The advantages of radical innovation are considered necessary for long-term success because they involve developing and applying new technologies, some of which can even change existing market structures. It is because they construct new functions for users who have a strong potential to lead to significant revenue and profit growth [5].

The innovation process is fundamental to provide competitive strength for the company. When innovation is successful in the company, it requires management development and exploring the knowledge of organizational resources [4]. Found that company performance, which is directly proportional to high growth, lies in their respective strategic approaches.

\section{Research Methodology}

This research used a qualitative method to examine the condition of natural objects. The primary method for this research is a qualitative case study analysis. This study chose a case study approach because it can explore and investigate the factors that can commercialize 
technology products successfully. In general, this method allows focused discussion around the problem being investigated, especially in terms of facilitating the disclosure of issues that are very important to the resource person [18].

The consideration of determining participants for case study research at BPPT is the sorting of employees who have a background of experience and have knowledge and understanding of issues regarding the commercialization of technological innovation products. Participants in question are actors in incubation activities or the Technology Readiness Level at the Center for Technology for Specific Areas and Innovation Systems. They also understand how research question, the researcher personally contacted 1-2 resource persons to conduct interviews based on job titles related to technology commercialization. The researcher contacted the focus group leader for focus group discussions, who then arranged for a focus group meeting. The selected focus group leader will schedule a suitable day and time to meet with the researcher.

\section{Data Analysis}

Inductive reasoning is used to analyze data because, according to [10)], the case study approach is rich in detail because it has many sources of evidence, making it suitable for inductively identifying additional variables and new hypotheses. In addition, the case study approach was adopted because research on technology commercialization could still be developed more complex than existing research. The purpose of this study was to determine the commercialization strategy in developing technology products at BPPT. After data collection is carried out, the recordings will be transcribed from sound to text [2].

Since one focus group meeting and two in-depth interviews were held, and voice recording was carried out, the researcher played the conversation's transcript several times to be immediately converted into text. The transcribed data in each of the in-depth interviews and FGDs was coded and entered into the main categories and sub-categories to make the research dimension. Among these sub-categories and categories have succeeded in making a relationship. The following four dimensions were found: the innovation process, the incubation process, the commercialization strategy, and the business process.

In-depth interviews are the main research instrument used by researchers to collect data. In-depth interviews are often conducted in conjunction with focus group discussions to obtain more detailed information. In this study, researchers used both data collection methods. Indepth interviews are a qualitative research technique that engages individuals intensively with a small number of respondents to explore their perspectives on a particular idea, program, or situation. In-depth interviews can be used for various purposes [10], including needs assessment, program refinement, problem identification, and strategic planning.

Meanwhile, focus group discussion was adopted because it facilitates collecting data quickly and has a lower cost to get more responses from many members [9]. Informants were selected based on purposive sampling. In each section of the innovation is created. Furthermore, at the Technology Service Center, participants are selected, consisting of employees responsible for marketing management, to commercialize BPPT products. Also involved are participants who understand and understand the implementation of standardization of innovation results and technology services at the Information Management Center, as a type of business activity. 


\section{Results}

\subsection{Background Information}

BPPT is established under the coordination of the Minister of Research, Technology, and Higher Education and has five deputies, each of which focuses on the study and application of technology. BPPT itself plays a role in Indonesia's development to increase competitiveness towards national independence. BPPT has a supporting implementation unit, including a department responsible for business processes and commercialization called the Technology Service Center (PUSYANTEK). The department where inventors came up with prototypes to make technology products was called the Center for Specific Area Technology and Innovation Systems (PTKSSI). The technical implementation unit for technology incubation process activities is in a business incubator called the Technology Incubator Center (BIT). A department that functions as standardization of innovation results and standardization of technology services called the Information Management Center (PMI).

\subsection{Innovation Process}

Findings of this study showed that the innovation process carried out by BPPT begins with the making of a Strategic Plan (RENSTRA), which refers to the VISION and MISSION. After the RENSTRA is made, the next process is to lower it to each deputy and serve as a Performance Determination (PENKIN). Then this PENKIN will be reduced again to each deputy to be worked on. The innovation process that occurs here is very structured, considering that BPPT is a technology innovation research institute in Indonesia that focuses on studying and applying technology. It supports [1]'s statement that maintaining innovation leadership requires changes in organizational structure and strategy. Changes in a more structured organization will increase innovation and creativity for inventors and innovators. The product development process carried out per each project will make the work more focused and completed quickly.

Furthermore, in launching an innovation strategy for generating ideas for making products, BPPT always leads to market demand. This is done so that the products they have made are expected to sell well in the market. One of the interviewees answered why they focus on selling products based on market demand is presented below:

“... Yes, we have high technology. So, for example, there are private companies or other interested industries and want our services, they can just come here, and we will help. But if it is like a usual appropriate technology, we will make it seen from the market and needs as well, especially for the people who use it".

Appropriate Technology here can be said as a form of application of high technology. So it can be explained that the use of high technology must be adjusted to the needs of the market and society to be appropriately utilized. This is similar to research by (16) that the critical factor determining a company's ability to develop and commercialize technological innovations successfully is understanding customer needs.

\subsection{Incubation Process}

The results obtained after conducting interviews show how the technology product incubation process at BPPT. This process is carried out at the Technology Incubator Center (BIT) under the auspices of PTKSSI, which was built by BPPT, which is shown to 
entrepreneurs or startups to help new businesses developing so they can become independent entrepreneurs. In its implementation system, BIT-BPPT divides 3 (three) stages of the incubation process, namely: pre-incubation, incubation, and post-incubation. The design of the incubation process in 3 stages is carried out in the form of business assistance such as providing office facilities, management consulting, technology provision, training, production testing, sales testing, and establishing synergies with universities, the private sector, research institutions and various parties that contribute to the business network, both locally and internationally. In addition, in its three stages, BIT-BPPT also routinely monitors and evaluates each activity carried out. This series of inquiry processes is a form of support for the acceleration of product commercialization for tenants or novice entrepreneurs. Due to this, tenants must be declared to have passed the three incubation stages first. The speakers convey the following regarding what facilities are obtained at the incubation stage:

“... Oo our facility? We have to prepare the incubation first, like preparing a roadmap, work program, legality, etc. The two have just conducted a production test followed by training and monitoring. After that, we have certification assistance for product commercialization later. We were followed by a consumer test, a new sales test, then monitoring and evaluation. If you have gone through various facilities, it is a sign that the product is certified and accepted by the market".

Based on [20] research, the incubation program is one of the main policy mechanisms to support innovation and provide a way to build relationships with the market while promoting products that are ready to be marketed.

\subsection{Commercialization Strategy}

Commercialization at BPPT can be successful if the innovative product can provide benefits in the form of materials and is used by the industry and offer return benefits. The return benefits referred to can be in the form of reputation or material to continue product and institutional development interests. The implementation of the use of this commercialization strategy starts with the planning stage. This planning consists of three stages: the data collection stage, the analysis stage, and the decision-making stage. In the data collection stage, internal, external, and competitive profile matrix factors will be evaluated.

Furthermore, after this stage, it is continued with the analysis stage, which analyzes various factors through the SWOT, BCG, Internal External, Space, and Grand Strategy matrix. After the analysis phase is complete, a decision can be made by using the Quantitative Strategic Planning Matrix. Also, the commercialization strategy used as a guideline by BPPT is to make technology products by understanding user needs or based on market needs in the sense of market-driven innovation. So it is hoped that commercializing the product will eventually make it more comfortable because the market and industry will be interested in the work. From the quadrant position analysis results in the IE Matrix, it was found that PUSYANTEK-BPPT had a five quadrant position, which was hold and maintains. So that the main strategies that can be suggested are product development and market penetration. By carrying out the three stages of planning, only then can it be decided what commercialization strategy will be most effective. It can be underlined that commercialization has also been achieved because BPPT, as an institution in the field of research and application of technology, has users by the institution's target. One of the employees answered who the partners who need technology products and services, as stated below: 
"The first one is government agencies, both central and local governments. Then our partners have something called State-Owned Enterprises (BUMN), private companies, then there are other institutional collaborations, usually from abroad".

From the explanation above, it can be seen that the target planned by BPPT for the need for technology products and services is a broad target market. Luckily, some of the four targets have "subscribed." Usually, in carrying out the commercialization strategy, their identification is carried out regarding their needs. The way BPPT sees the requirements related to technological innovation for government agencies and local governments is expressed by other employees below:

\footnotetext{
"We identify themselves what their needs are, for example, from government agencies what their needs are there. In the local government, we see what the region's potential is what we can strengthen. For example, it is strong in the agricultural sector, and we will encourage the agricultural sector. Then if it is strong in the mining sector, we will encourage working in the mining sector, and so on".
}

Based on the explanation above, it can be seen that the strategy in knowing the needs of the target market is to carry out a separate external mapping. That way, BPPT can understand what those who need help with technological innovation. The commercialization strategy carried out by BPPT is in line with the research of [17], which states that providers must understand customer needs that they are not aware of to obtain requests and responses from customers.

\subsection{Business process}

When launching a commercialization strategy, it also requires a series of business process stages to support product success. This business process consists of 10 stages, starting from research, technology disclosure, assessment, intellectual property protection, technology marketing, selecting the best partner, cooperation agreement, project management, payment and royalties, and reinvest. At the stage of selecting the best partner, PUSYANTEK will select partners that have the potential to collaborate using a technology resulting from engineering activities. This selection is carried out to see the capacity and capability of partners in cooperation activities to produce and distribute these technological innovation products and services to the regions and the industry to lead to sustainability. This stage requires a thorough examination of the background of the business partners who will cooperate. One of the employees explains what backgrounds must be checked before starting cooperation, as stated below:

"After conducting a business meeting, there is not only one person who are interested. There must be some who are interested, right? So we are here to select the best partner. So here we are assessing this company, whether it is financially healthy or not. Judging from the overall background of the company, how about legality. Then in terms of production capabilities, he is".

The business strategy carried out by BPPT is in line with research from [12] that selecting external business partners during the commercialization process of new technology products will accelerate product delivery to the market and increase business knowledge capabilities. However, sometimes unexpected things arise during the business process, such as mistakes in market analysis and inaccurate background checks on partners. One example is losing quickly in the mass production process because competitors have produced a similar product, described by the following female employees: 
"There are a lot of industries. Only one succeeded. So he's not good at marketing. So it's not the product that failed. But many other sectors produce the same thing".

In addition, this business process is supported by PUSYANTEK and PMI by using an IT Business Process Management infrastructure called the BPPT Enterprise Architecture. It is hoped that IT-based Enterprise Architecture can make it easier for employees to be accessed and coordinated.

\subsection{Framework of Commercialization Strategy of Technology Innovation Products}

Figure 1 shows the strategic framework adopted by BPPT for successful commercialization. As discussed, BPPT uses several processes before launching a commercialization strategy. Some of the processes include the innovation process, the incubation process, and the business process. Besides, what is no less important is implementing the commercialization strategy for the success of commercialization.

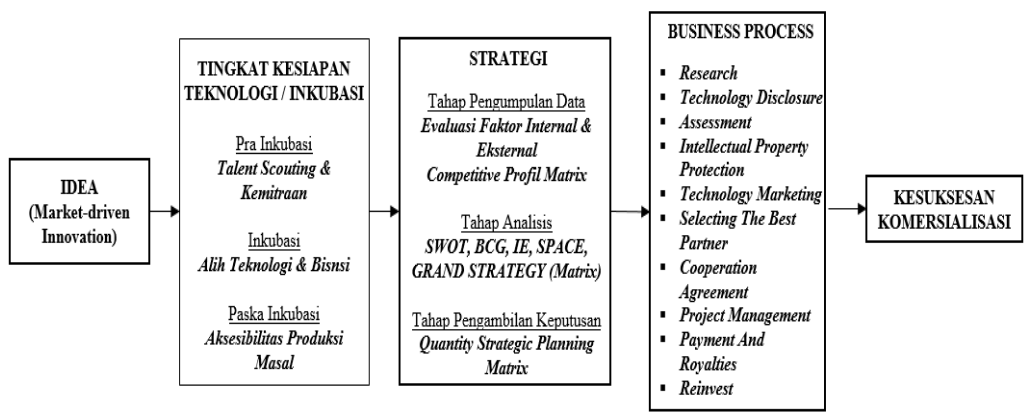

Fig. 1. Commercialization Process Framework

\section{Conclusions and Future Work}

The commercialization strategy is carried out so that the market can accept technology products that have been developed by BPPT. Based on this, BPPT carries out a series of supporting processes, namely an innovation process to create an idea, an incubation process for product development and maturation, and a business process expected to benefit in the form of name re-investment. To make the concept of determining the commercialization strategy is carried out in 3 stages, namely the data collection stage, the analysis stage, and the decision-making stage so that the final result of the strategic decision is deemed suitable and following existing conditions. Furthermore, commercializing the product has been a success because BPPT already has users in line with institutional targets such as BUMN, private industry, central and regional governments, and other institutions. There are also new insights and perspectives that the commercialization of technology products from a research institute is more successful if it is also supported by the preparation of a clear, planned, and measured strategic plan so that strategies in increasing the role of technology through technological innovation and services will be in line with the direction of national development. In the future, we propose research on commercialization strategies from a variety of business perspectives and providers. Applying the commercialization model used to different industries certainly needs an adjustment of the industry's commercialization model. 


\section{References}

[1] F. T. Rothaermel, 'Competitive advantage in technology intensive industries', $A d v$. Study Entrep. Innov. Econ. Growth, vol. 26, pp. 233-256, 2016, doi: 10.1108/S1048473620160000026008.

[2] W. E. Forum, The Global Competitiveness Report 2019, vol. 44, no. 10. World Economic Forum, 2019.

[3] N. Khalil Zadeh, M. Khalilzadeh, M. Mozafari, M. Vasei, and A. Amoei Ojaki, 'Challenges and difficulties of technology commercialization - a mixed-methods study of an industrial development organization', Manag. Res. Rev., vol. 40, no. 7, pp. 745767, 2017, doi: 10.1108/MRR-08-2016-0192.

[4] Kompas, 'Hilirisasi dan Komersialisasi Riset agar Terkoordinasi', 2019.

[5] U. Lichtenthaler, 'Opening up strategic technology planning: Extended roadmaps and functional markets', Manag. Decis., vol. 46, no. 1, pp. 77-91, 2008, doi: 10.1108/00251740810846752.

[6] S. Wakeman, 'Profiting from Technological Capabilities: Technology Commercialization', no. October, p. 49, 2015.

[7] K. Parker and M. Mainelli, 'Great mistakes in technology commercialization', Strateg. Chang., vol. 10, no. 7, pp. 383-390, 2001, doi: 10.1002/jsc.560.

[8] R. A. Siegel, S. O. Hansen, and L. H. Pellas, 'Accelerating the Commercialization of Technology: Commercialization Through Co-operation', Ind. Manag. Data Syst., vol. 95, no. 1, pp. 18-26, 1995, doi: 10.1108/02635579510079425.

[9] M. A. Hitt, R. D. Ireland, and R. E. Hoskisson, Competitiveness \& Globalization, 9th ed. Canada, 2011.

[10] M. Plessis and S. Africa, 'The role of knowledge management in innovation The Authors', J. Knowl. Manag., vol. 14, no. 4, pp. 20-29, 2007.

[11] A. Ghobadian, N. O'Regan, D. Gallear, and H. Viney, 'Strategy and Performance', p. $331,2003$.

[12] G. Symon and C. Cassell, 'Introduction: The Context of Qualitative Organizational Research', Qual. Organ. Res. Core Methods Curr. Challenges, pp. 1-12, 2017, doi: 10.4135/9781526435620.n1.

[13] T. Pacho, 'Exploring Participants' Experiences Using Case Study', Int. J. Humanit. Soc. Sci., vol. 5, no. 4, pp. 44-53, 2015.

[14] A. Duranti, 'Transcripts, like shadows on a wall. Mind, Culture and Activity.', vol. 13, no. 4, pp. 301-310, 2006.

[15] P. P. Conceição Pedro, Hamill Dennis, 'Innovative science and technology commercialization strategies at 3M: a case study.', J. Eng. Technol. Manag., vol. 19, no. 1 , pp. $25-38,2002$.

[16] S. F. Slater and J. J. Mohr, 'Successful development and commercialization of technological innovation: Insights based on strategy type', J. Prod. Innov. Manag., vol. 23, no. 1, pp. 26-33, 2006, doi: 10.1111/j.1540-5885.2005.00178.x.

[17] J. Wonglimpiyarat, 'Incubator policy to support entrepreneurial development, technology transfer and commercialization', World J. Entrep. Manag. Sustain. Dev., vol. 10, no. 4, pp. 334-351, 2014, doi: 10.1108/wjemsd-03-2014-0008.

[18] J. T. Pellikka and P. Malinen, 'Business models in the commercialization processes of innovation among small high-technology firms', Int. J. Innov. Technol. Manag., vol. 11, no. 2, 2014, doi: 10.1142/S0219877014500072. 